\title{
Gardnerella vaginalis
}

National Cancer Institute

\section{Source}

National Cancer Institute. Gardnerella vaginalis. NCI Thesaurus. Code C86410.

A species of facultatively anaerobic, Gram positive, rod shaped bacteria assigned to the phylum Actinobacteria. This species has a very thin cell wall that may appear Gram negative under the microscope. G. vaginalis may be found in the genital tract or pharynx of humans and is a causative agent of bacterial vaginosis. 